\title{
Circumferential Locations of Different Shapes of Short-segment Barrett's Esophagus
}

\author{
Kyoichi Adachi ${ }^{1}$, Tomoko Mishiro ${ }^{1}$, Shino Tanaka ${ }^{1}$ and Yoshikazu Kinoshita ${ }^{2}$
}

\begin{abstract}
Objective To clarify the relationship between the shape and circumferential location of non-circumferential short-segment Barrett's esophagus (SSBE).

Methods We examined 3,788 subjects (2,497 males, 1,291 females; mean age 52.4 years) who underwent upper GI endoscopy as part of a detailed medical checkup. The presence of columnar-appearing mucosa $\geq 10$ $\mathrm{mm}$ long in the distal esophagus was diagnosed as BE and then divided into circumferential and noncircumferential localized types. Localized SSBE was further divided into round and sharp types based on the shape of the proximal margin.

Results SSBE was endoscopically observed in 197 subjects (5.2\%). The numbers of patients with circumferential SSBE, round localized SSBE, and sharp localized SSBE were 38, 114 and 69, respectively. Round and sharp types of localized SSBE were simultaneously observed in 25 patients. Reflux esophagitis was more frequently observed in subjects with BE, regardless of type, in comparison to those without BE. Round localized SSBE was found mainly in the left posterior wall of the esophagus in a location similar to the main area of the esophageal cardiac glands. In contrast, sharp localized SSBE was observed mainly in the right anterior wall of the esophagus in a location similar to that of esophageal mucosal injury caused by mild type reflux esophagitis.

Conclusion The location differs between round and sharp localized SSBE, possibly due to differences in the process of BE development.
\end{abstract}

Key words: Barrett's esophagus, SSBE, reflux esophagitis, GERD, esophageal cardiac gland

(Intern Med 56: 1937-1942, 2017)

(DOI: 10.2169/internalmedicine.56.8260)

\section{Introduction}

The rate of incidence of adenocarcinoma arising from Barrett's esophagus (BE) has increased over the past two decades in Western countries, although the disease remains rare in Japan and other Asian countries (1-3). In contrast, the incidence of gastroesophageal reflux disease (GERD) has been increasing over the past few decades in Asian countries, and the development of adenocarcinoma from $\mathrm{BE}$ has been an important issue in Asian patients (4-7). Indeed, the rate of incidence of adenocarcinoma development in the esophagogastric junction has also been gradually increasing in Asia (3, 7-10). In Japan, while the prevalence of long- segment Barrett's esophagus (LSBE) is rare, the number of cases of adenocarcinoma developing from short-segment Barrett's esophagus (SSBE) has increased (3, 7-12). As a result, patients with SSBE are considered to be the main population in Asian countries requiring endoscopic surveillance to detect esophageal adenocarcinoma.

$\mathrm{BE}$ is an acquired condition resulting from gastroesophageal reflux disease $(13,14)$. Indeed, the shape of SSBE sometimes resembles that of esophageal mucosal injury matching Los Angeles (LA) classification (15) A and B grade reflux esophagitis, which sharply extends to the proximal part of the esophagus. Previously, Nakanishi et al. conducted a detailed histological study of surgical specimens and reported that columnar epithelial islands arising from

${ }^{1}$ Health Center, Shimane Environment and Health Public Corporation, Japan and ${ }^{2}$ The Second Department of Internal Medicine, Shimane University Faculty of Medicine, Japan

Received for publication September 12, 2016; Accepted for publication December 11, 2016

Correspondence to Dr. Kyoichi Adachi, adachi@kanhokou.or.jp 


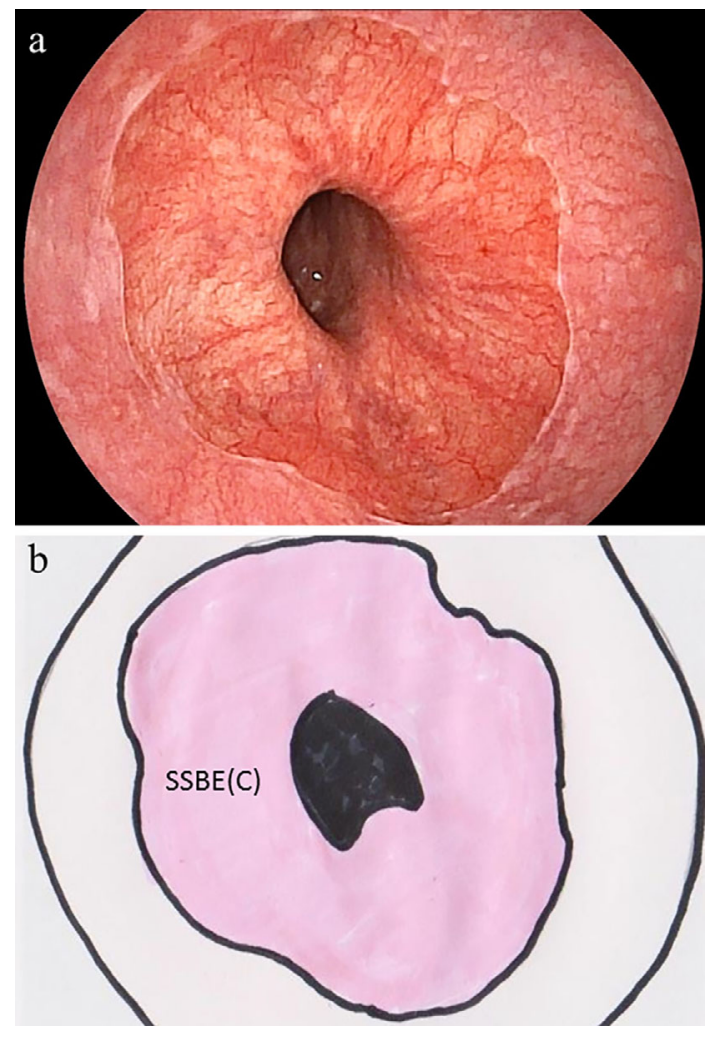

Figure 1. (a) Endoscopic image and (b) proposed schematic illustration of the circumferential location of short-segment Barrett's esophagus (SSBE). The pink area in the illustration indicates circumferential SSBE [SSBE (C)].

the esophageal cardiac glands play an important role in the development of SSBE (16). Esophageal cardiac glands can be visualized as yellow-colored elevated areas in the distal esophagus using endoscopy (17-19). We recently reported that the location of esophageal cardiac glands was mainly on the left-posterior side of the esophageal wall, which is opposite the main site of mucosal injury in patients with LA grade A or B reflux esophagitis (19-22). Therefore, there may be differences regarding the shape and circumferential location between SSBE arising from an esophageal cardiac gland and that arising during the healing process of esophageal mucosal injury caused by gastric acid reflux.

In the present study, we attempted to determine the circumferential location of SSBE after dividing noncircumferential localized SSBE into two types (round and sharp) based on the shape of the proximal margin.

\section{Materials and Methods}

The study subjects were individuals who visited the Health Center of Shimane Environment and Health Public Corporation for a detailed medical checkup between April 2014 and March 2015. The majority was socially active and productive and considered to be socioeconomically middle class. Subjects with a history of gastric surgery were not included in this study, and only the first endoscopic examination was analyzed in those who underwent upper GI endo- scopy twice during the study period. Subjects who had taken medications such as proton pump inhibitors or $\mathrm{H} 2$ receptor antagonists were excluded. All upper endoscopic examinations were performed by licensed experienced endoscopists (K.A., T.M., S.T.) using an EG-530NW or EG-530NP endoscope (Fujifilm, Tokyo, Japan). At our institute, all upper endoscopic examinations are performed in an unsedated condition without any anti-cholinergic drugs, and the endoscope is mainly inserted transnasally.

The criterion for an endoscopic diagnosis of Barrett's epithelium was the observation of columnar-appearing mucosa in the area between the squamocolumnar and esophagogastric junction. In this study, the esophagogastric junction was defined as the distal margin of the palisade vessels, based on the criteria of The Japan Esophageal Society (23), while endoscopically detected columnar-appearing mucosa of the distal esophagus was diagnosed as BE when the mucosa was $\geq 10 \mathrm{~mm}$ long, since a detailed endoscopic observation could demonstrate the presence of $\mathrm{BE}$ under $10 \mathrm{~mm}$ and the presence of BE under $10 \mathrm{~mm}$ is recognized differently based on the conditions of the endoscopic observation $(24,25)$. BE with a circumferential length $>3 \mathrm{~cm}$ was defined as LSBE, while that with a length of 1-3 cm was defined as SSBE in this study. When SSBE was endoscopically observed, we designated that as circumferential or localized type, based on the shape. In addition, localized SSBE was further divided into round and sharp types, based on the shape of the proximal margin (Fig. 1-3). The circumferential location of localized SSBE in the esophageal wall was determined and expressed according to the numbers on a clock face. For example, localized SSBE in the anterior wall was considered to be located in the 12 o'clock position, while that in the right wall was located in the 3 o'clock position. When multiple areas of localized SSBE were present, the circumferential positions of all were recorded. Occasionally, the round type of localized SSBE extended in a transverse manner. In the present study, SSBE in all directions was recorded.

The endoscopic findings of reflux esophagitis were evaluated using the LA classification (15), and individuals with a grade of A, B, C, or D were judged as positive. The size of the diaphragmatic hiatus was assessed during endoscopy by comparing the width of the cardiac opening with the diameter of the shaft used for the observation at the cardiac portion and then assigned to 1 of 3 groups $(<1.0,1.0-2.0,>2.0$ $\mathrm{cm}$ ). The degree of gastric mucosal atrophy was endoscopically evaluated using the classification of Kimura and Takemoto, with gastric mucosal atrophy divided into 6 groups (C1, C2, C3, O1, O2, O3) (26). It has been shown that the gastric acid secretion in patients with gastric mucosal atrophy decreases in a successive manner from $\mathrm{C} 1$ to O3 (27). In this study, we defined C1-3 as closed-type and O1-O3 as open-type gastric mucosal atrophy. Three expert endoscopists (K.A., T.M., S.T.) simultaneously reviewed all of the endoscopic images from each subject, and the diagnosis of each endoscopic finding was made. If there were any inconsistencies in the reading of the endoscopic images be- 


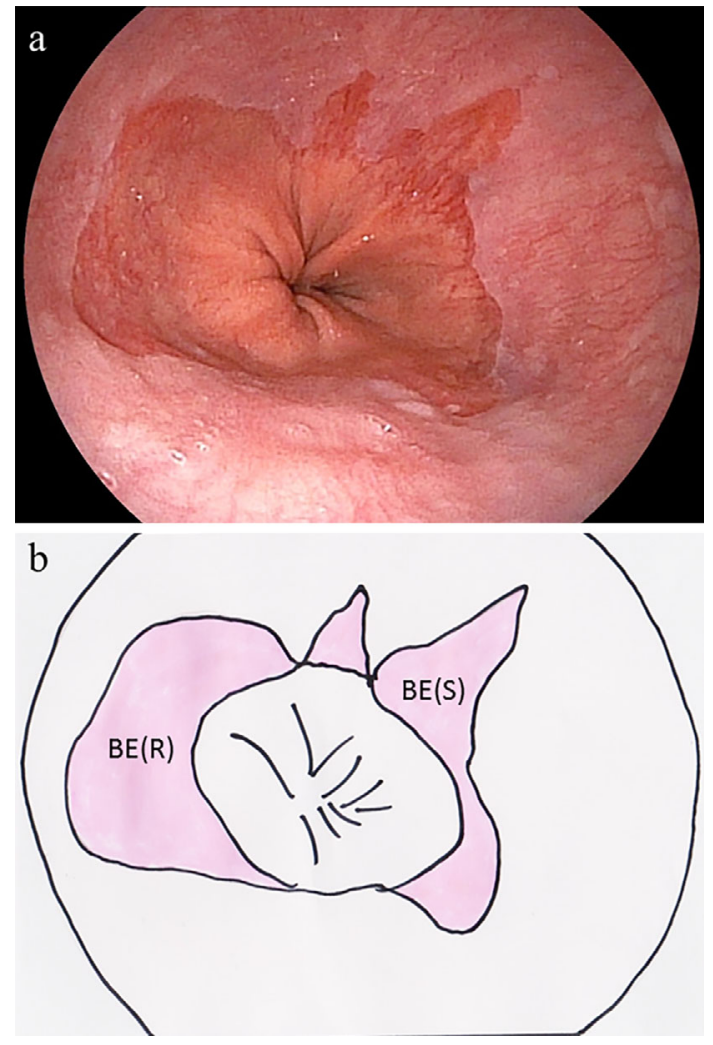

Figure 2. (a) Endoscopic image and (b) schematic illustration of localized short-segment Barrett's esophagus (SSBE). The pink area in the illustration indicates SSBE. Both sharp (S) and round $(R)$ types of localized SSBE are shown.

tween the three endoscopists, the final diagnosis was decided by one endoscopist (K.A.).

Statistical analyses were performed using the chi-squared and Mann-Whitney U tests with the Stat View 5.0 software program (Abacus Concepts, Berkeley, USA) for Macintosh. Differences of $p<0.05$ were considered to be statistically significant.

This study was performed in accordance with the Declaration of Helsinki, and the protocol was approved by the ethics committee of the Shimane Environment and Health Public Corporation. Written informed consent indicating that clinical data would be used for a clinical study without the release of individual information was obtained from all subjects before performing the medical checkups.

\section{Results}

A total of 3,788 individuals (2,497 males, 1,291 females; mean age 52.4 years) who underwent an upper GI endoscopy examination between April 2014 and March 2015 were enrolled as subjects. Of those, 198 (5.2\%) were endoscopically found to have $B E \geq 10 \mathrm{~mm}$ in length. Only 1 had LSBE, and that subject was excluded from the analysis. There were 38 subjects with circumferential SSBE, while 114 had round localized SSBE and 69 sharp localized SSBE. The round and sharp types of localized SSBE were simultaneously observed in 25 cases, so these cases were as-

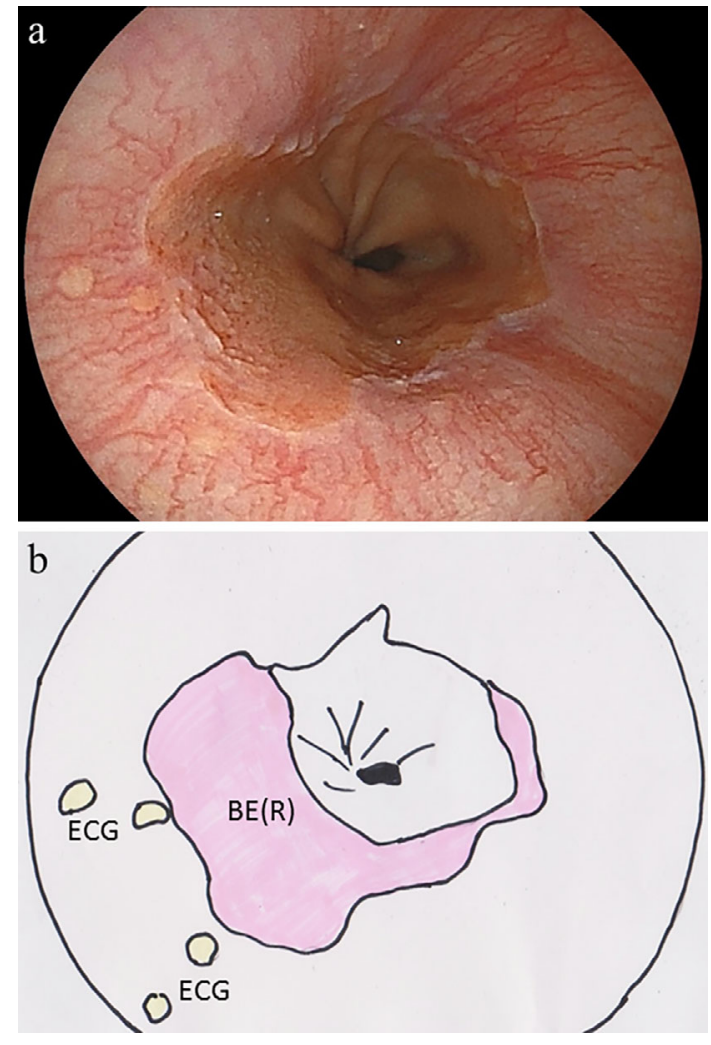

Figure 3. (a) Endoscopic image and (b) schematic illustration of round type localized short-segment Barrett's esophagus [SSBE (R)]. The pink area in the illustration indicates SSBE, and the yellow spots indicate the esophageal cardiac glands. Some cases with SSBE (R) had endoscopically visible esophageal cardiac glands.

signed to both type groups. The characteristics of the subjects by type of BE are shown in Table. On comparing the subjects with and without BE, those with circumferential SSBE tended to be older. The proportion of males, habitual drinkers and current smokers among the cases with sharp localized SSBE were greater than among those without BE. Reflux esophagitis was more frequently observed in cases with SSBE regardless of type than in those without BE. Furthermore, the size of the diaphragmatic hiatus was larger in cases with circumferential SSBE and sharp localized SSBE than in other types. The degree of gastric mucosal atrophy was not markedly different between the groups.

When the circumferential locations of SSBE were examined, there was an apparent difference between the round and sharp SSBE (Fig. 4). Round localized SSBE was mainly located in the left posterior wall of the esophagus, whereas sharp localized SSBE was primarily localized in the right anterior wall of the esophagus.

\section{Discussion}

The prevalence of LSBE in Asian countries, including Japan, is lower than in Western countries, while SSBE is more common in Asia (7-9, 11, 28-30). The malignant potential of SSBE is high, and the majority of esophageal adenocarci- 
Table. Characteristics of Subjects without and with Each Type of SSBE.

\begin{tabular}{lcccc}
\hline & Without BE & $\begin{array}{c}\text { With circumferential } \\
\text { SSBE }\end{array}$ & $\begin{array}{c}\text { With round localized } \\
\text { SSBE }\end{array}$ & $\begin{array}{c}\text { With sharp localized } \\
\text { SSBE }\end{array}$ \\
\hline Gender (male/female) & $2,356 / 1,235$ & $29 / 9$ & $73 / 41$ & $56 / 13^{*}$ \\
& $(65.6 / 34.4)$ & $(76.3 / 23.7)$ & $(64.0 / 36.0)$ & $(81.2 / 18.8)$ \\
Age in years (mean \pm SD) & $52.3 \pm 9.2$ & $57.6 \pm 8.4 *$ & $53.4 \pm 9.2$ & $52.7 \pm 9.6$ \\
BMI & $22.9 \pm 3.3$ & $23.0 \pm 2.7$ & $22.6 \pm 3.0$ & $22.9 \pm 3.3$ \\
Habitual drinking & $2,039(56.8)$ & $22(57.9)$ & $75(65.8)$ & $47(68.1)$ \\
Current smoking & $725(20.2)$ & $12(31.6)$ & $22(19.3)$ & $15(21.7)$ \\
\hline Reflux esophagitis & $335(9.3)$ & $11(28.9)^{*}$ & $21(18.4)^{*}$ & $21(30.4)^{*}$ \\
Size of diaphragmatic hiatus & & & & \\
$\quad<1.0 / 1.0-2.0 />2.0 \mathrm{~cm}$ & $2,863 / 670 / 58$ & $16 / 20 / 2 *$ & $96 / 16 / 2$ & $56 / 13 / 0$ \\
& $(79.7 / 18.7 / 1.6)$ & $(42.1 / 52.6 / 5.3)$ & $(84.2 / 14.0 / 1.8)$ & $(81.2 / 18.8 / 0)$ \\
Gastric mucosal atrophy & & & & $61 / 8$ \\
$\quad$ Closed / open type & $3,072 / 519$ & $31 / 7$ & $96 / 18$ & $(88.4 / 11.6)$ \\
& $(85.5 / 14.5)$ & $(81.6 / 18.4)$ & $(84.2 / 15.8)$ & \\
\hline
\end{tabular}

BE: Barrett's esophagus, SSBE: short segment Barrett's esophagus, BMI: body mass index. Habitual drinking: drinking at 3 or more days per week. With anti-secretory drugs: Subjects with medication of proton pump inhibitors or $\mathrm{H} 2$ receptor antagonists. Closed and open type of gastric mucosal atrophy: C1-3 and O1-3 of the classification of Kimura and Takemoto.

Data are shown as the mean \pm SD. Values in parentheses are percentages of cases. ${ }^{*}$ Compared to subjects without $\mathrm{BE}(\mathrm{p}<0.05$ ).
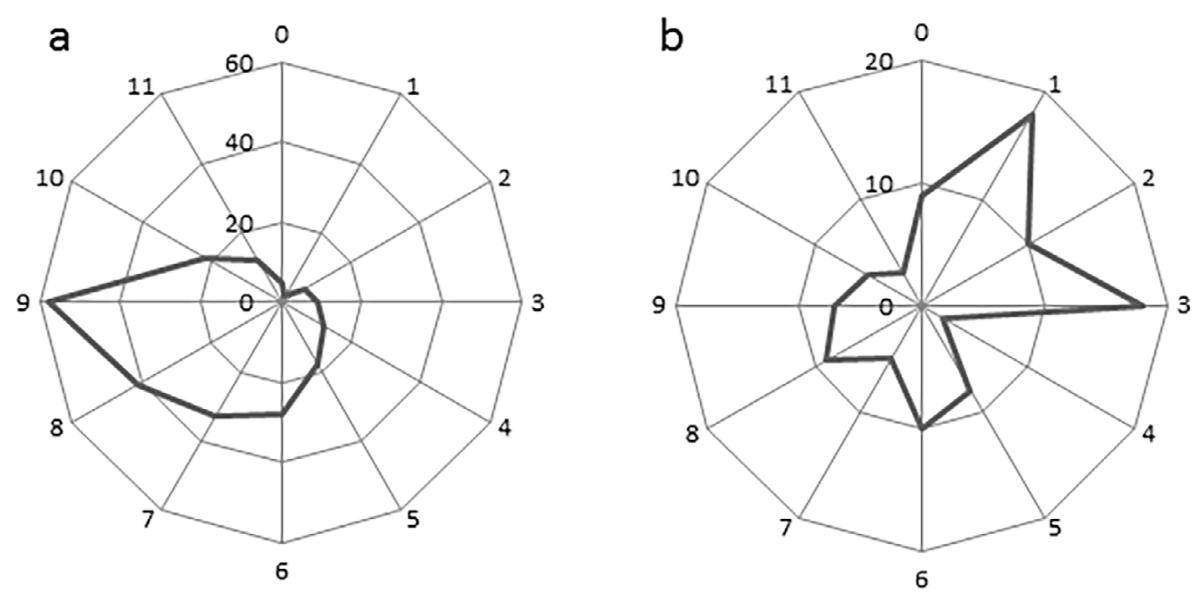

Figure 4. Circumferential locations of (a) round and (b) sharp localized short-segment Barrett's esophagus (SSBE). The locations are shown based on a clock face orientation. The numbers represent the number of SSBE lesions on each side of the esophageal wall.

noma cases in Asian patients have been reported to originate from $\operatorname{SSBE}(3,7-10)$; as such, endoscopic surveillance is considered to be important for detecting early-stage esophageal adenocarcinoma in both LSBE and SSBE cases. In the present study, we made a diagnosis of BE when the length was $\geq 10 \mathrm{~mm}$ and noted a prevalence of $5.2 \%$ in subjects who underwent an endoscopic examination as part of an annual medical checkup. The prevalence of BE in our subjects was lower than that in other Japanese groups, including recent endoscopic studies that found that 20.8-85.9\% of participants had BE, including ultra-short-segment BE $(11,12)$. Therefore, a majority of endoscopically observed cases of SSBE in Japanese subjects seems to be $<10 \mathrm{~mm}$ in length. In addition, the prevalence of SSBE in subjects who underwent upper GI endoscopy for a detailed medical checkup might be lower than that in patients who visited the clinics due to upper gastrointestinal symptoms.
Gastric acid reflux is considered to have an important relationship with the incidence of $\operatorname{BE}(12,13)$, although the precise mechanism of its generation remains unclear. Several factors, such as gender, aging, obesity, alcohol intake, smoking, the size of the diaphragmatic hiatus and gastric mucosal atrophy, have been repeatedly shown to correlate with gastric acid reflux (4-6). In this study, we observed greater proportions of male subjects, habitual drinkers and current smokers among subjects with sharp localized SSBE than among those without BE. In addition, the numbers of cases having reflux esophagitis among subjects with all types of SSBE were greater than among those without BE. Furthermore, the size of the diaphragmatic hiatus was larger in cases with circumferential SSBE and sharp localized SSBE than those with other types. Therefore, gastric acid reflux is considered to have an important role in the development of all types of SSBE, although the degree of gastric mucosal 
atrophy was not markedly different between the subjects with and without SSBE.

To our knowledge, this study demonstrated for the first time the difference in the main location between round and sharp localized SSBE. Previously, esophageal mucosal injury in mild-type (LA grade A, B) reflux esophagitis cases was found to be mainly located in the right anterior wall of the lower esophagus (20-22), while our findings showed that sharp localized SSBE also exists mainly in that location. Male predominance, as well as frequent drinking and smoking, were noted in the subjects with sharp localized SSBE, characteristics that have been repeatedly reported to be observed in patients with reflux esophagitis (4-6, 31-35). In addition, the shape of sharp localized SSBE resembles that of esophageal longitudinal mucosal injury associated with mild reflux esophagitis, indicating that it is mainly formed during the healing process of esophageal mucosal injury in subjects with mild reflux esophagitis. In contrast, round localized SSBE mainly exists in the left posterior wall of the esophagus. This location was similar to that of the esophageal cardiac glands, as was recently reported by Hanada et al. (19). In addition, the esophageal cardiac glands have been occasionally observed in cases with round localized SSBE. Nakanishi et al. performed a detailed histological study of surgical specimens and reported that columnar epithelial islands arising from the esophageal cardiac glands have an important role in the development of SSBE (16). Therefore, we believe that round, localized SSBE mainly originates from those glands. Our speculations concerning the different origins of BE between sharp and round localized SSBE should be confirmed in a long-term endoscopy observation study in cases with mild-type reflux esophagitis and the presence of esophageal cardiac glands.

Our study has several limitations, including its crosssectional nature and one-year period of observations, which prevented us from examining time-course changes, although the morphological shape of BE can change over an extended period of time. Another important issue is how circumferential BE develops, and the morphological characteristics of $\mathrm{BE}$ in young and older subjects may provide additional information to consider when discussing its development. The majority of our subjects was socially active and productive, with relatively few very young and elderly individuals. A large-scale prospective population-based study is needed to clarify the morphological changes of BE associated with aging. In addition, the inter-observer agreement in the diagnosis of shape and location of SSBE could not evaluated in this study, since all three endoscopists at our institute simultaneously reviewed all endoscopic images from each subject to determine the shape and location of SSBE. Furthermore, we did not perform histological examinations to detect the presence of intestinal metaplasia, which is considered to be important for the diagnosis of BE in the US and European countries, as well as for determining the risk of progression to adenocarcinoma $(24,25)$. Therefore, we did not examine the difference between round and sharp localized SSBE in the risk of progression to adenocarcinoma. However, previous studies have reported that adenocarcinomas progressing from SSBE were mainly located in the right anterior wall of the esophagus $(36,37)$, which corresponds to the sharp type of localized SSBE shown in our study. Thus, the risk of progression to adenocarcinoma might be higher in cases with sharp localized SSBE than in those with round localized SSBE. Recently, the presence of histological intestinal metaplasia has been evaluated based on the mucosal patterns of $\mathrm{BE}$, which can be determined via both magnified and nonmagnified endoscopic observations (38-42). The difference in the histology and/or mucosal patterns of different types of SSBE should be investigated to clarify the associated risk of progression to adenocarcinoma.

In conclusion, we observed a difference in the location between round and sharp localized SSBE. In subjects with round localized SSBE, the location of BE was mainly in the left posterior wall of the esophagus, whereas that in cases with sharp localized SSBE was mainly in the right anterior esophagus wall. The differences in the location between round and sharp localized SSBE might be caused by differences in the process of BE development.

\section{The authors state that they have no Conflict of Interest (COI).}

\section{Acknowledgement}

We wish to thank Ms. Yoko Komori, Ms. Kiyoe Kawase, Ms. Yuki Funaki, Ms. Noriko Yamauchi and Mr. Masakazu Fukushima in Shimane Environment and Health Public Corporation, and Ms. Rika Tohma and Ms. Keiko Masuzaki in Second Department of Internal Medicine, Shimane University Faculty of Medicine for their technical support.

\section{References}

1. Pohl H, Welch HG. The role of overdiagnosis and reclassification in the marked increase of esophageal adenocarcinoma incidence. J Natl Cancer Inst 97: 142-146, 2005.

2. Everhart JE, Ruhl CE. Burden of digestive diseases in the United States part I: overall and upper gastrointestinal diseases. Gastroenterology 136: 376-386, 2009.

3. Hongo M, Nagasaki Y, Shoji T. Epidemiology of esophageal cancer: orient to occident. Effects of chronology, geography and ethnicity. J Gastroenterol Hepatol 24: 729-735, 2009.

4. Fujiwara Y, Arakawa T. Epidemiology and clinical characteristics of GERD in the Japanese population. J Gastroenterol 44: 518-534, 2009.

5. Kinoshita Y, Adachi K, Hongo M, Haruma K. Systematic review of the epidemiology of gastroesophageal reflux disease in Japan. J Gastroenterol 46: 1092-1103, 2011.

6. Wong BC, Kinoshita Y. Systematic review on epidemiology of gastroesophageal reflux disease in Asia. Clin Gastroenterol Hepatol 4: 398-407, 2006.

7. Amano Y, Kinoshita Y. Barrett esophagus: perspectives on its diagnosis and management in Asian populations. Gastroenterol Hepatol (N Y) 4: 45-53, 2008.

8. Yeh C, Hsu CT, Ho AS, Sampliner RE, Fass R. Erosive esophagitis and Barrett's esophagus in Taiwan: a higher frequency than expected. Dig Dis Sci 42: 702-706, 1997.

9. Chen PH. Review: Barrett's oesophagus in Taiwan. J Gastroenterol Hepatol 12: S19-S22, 1997. 
10. Kusano C, Gotoda T, Khor CJ, et al. Changing trends in the proportion of adenocarcinoma of the esophagogastric junction in a large tertiary referral center in Japan. J Gastroenterol Hepatol 23: $1662-1665,2008$

11. Kawano T, Kouzu T, Ohara S, Kusano M. The prevalence of Barrett's mucosa in the Japanese. Gastroenterol Endosco 47: 951-961, 2005 (in Japanese, Abstract in English).

12. Sugimoto $H$, Kawai $T$, Naito $S$, et al. Surveillance of shortsegment Barrett's esophagus using ultrathin transnasal endoscopy. J Gastroenterol Hepatol 30 (Suppl 1): 41-45, 2015.

13. Sharma P. Clinical practice. Barrett's esophagus. N Engl J Med 361: 2548-2556, 2009.

14. Westhoff B, Brotze S, Weston A, et al. The frequency of Barrett's esophagus in high-risk patients with chronic GERD. Gastrointest Endosc 61: 226-231, 2005.

15. Lundell LR, Dent J, Bennett JR, et al. Endoscopic assessment of oesophagitis: clinical and functional correlates and further validation of the Los Angeles classification. Gut 45: 172-180, 1999.

16. Nakanishi Y, Saka M, Eguchi T, Sekine S, Taniguchi H, Shimoda T. Distribution and significance of the oesophageal and gastric cardiac mucosae: a study of 131 operation specimens. Histopathology 51: 515-519, 2007.

17. Yagi K, Aruga Y, Nakamura A, Sekine A. An endoscopic and magnifying endoscopic study of esophageal cardiac gland: what role does esophageal cardiac gland play at the esophago-cardiac junction? Dig Endosc 17 (Supple): S11-S16, 2005.

18. Yagi K, Nakamura A, Sekine A, Umezu H. The prevalence of esophageal cardiac glands: relationship with erosive esophagitis and nonerosive reflux disease (NERD) in Japanese patients. Endoscopy 38: 652-653, 2006

19. Hanada K, Adachi K, Mishiro $T$, et al. Relationship between esophageal cardiac glands and gastroesophageal reflux disease. Intern Med 54: 91-96, 2015.

20. Katsube T, Adachi K, Furuta K, et al. Difference in localization of esophageal mucosal breaks among grades of esophagitis. J Gastroenterol Hepatol 21: 1656-1659, 2006.

21. Yamagishi H, Koike $T$, Ohara $S$, et al. Tongue-like Barrett's esophagus is associated with gastroesophageal reflux disease. World J Gastroenterol 14: 4196-4203, 2008.

22. Ohara S, Furuta K, Adachi K, et al. Radially asymmetric gastroesophageal acid reflux in the distal esophagus - examinations with novel $\mathrm{pH}$ sensor catheter equipped with $8 \mathrm{pH}$ sensors. J Gastroenterol 47: 1221-1227, 2012.

23. Japanese Classification of Esophageal Cancer (The 10th Edition/ Revised Version). The Japan Esophageal Society, Ed. Kanehara Shuppan, Tokyo, 2008: 40-42.

24. Fitzgerald RC, di Pietro M, Ragunath K, et al. British Society of Gastroenterology guidelines on the diagnosis and management of Barrett's oesophagus. Gut 63: 7-42, 2014.

25. Shaheen NJ, Falk GW, Iyer PG, Gerson LB. ACG Clinical Guideline: Diagnosis and Management of Barrett's Esophagus. Am J Gastroenterol 111: 30-50, 2016.

26. Kimura K, Takemoto T. An endoscopic recognition of the atrophic border and its significance in chronic gastritis. Endoscopy 1: 8797, 1969.

27. Miki K, Ichinose M, Shimazu A. Serum pepsinogen as a screening test of extensive chronic gastritis. Gastroenterol Jpn 22: 133-141,
1987.

28. Sharma P, Morales TG, Bhattacharyya A, Garewal HS, Sampliner RE. Dysplasia in short-segment Barrett's esophagus: a prospective 3-year follow-up. Am J Gastroenterol 92: 2012-2016, 1997.

29. Rudolph RE, Vaughan TL, Storer BE, et al. Effect of segment length on risk for neoplastic progression in patients with Barrett esophagus. Ann Intern Med 132: 612-620, 2000.

30. Desai TK, Krishnan K, Samala N, et al. The incidence of oesophageal adenocarcinoma in non-dysplastic Barrett's oesophagus: a meta-analysis. Gut 61: 970-976, 2012.

31. Shimazu T, Matsui T, Furukawa K, et al. A prospective study of the prevalence of gastroesophageal reflux disease and confounding factors. J Gastroenterol 40: 866-872, 2005.

32. Mishima I, Adachi K, Arima N, et al. Prevalence of endoscopically negative and positive gastroesophageal reflux disease in the Japanese. Scand J Gastroenterol 40: 1005-1009, 2005.

33. Fujimoto K. Prevalence and epidemiology of gastro-oesophageal reflux disease in Japan. Aliment Pharmacol Ther 20 (Suppl 8): 58, 2004.

34. Meining A, Classen M. The role of diet and lifestyle measures in the pathogenesis and treatment of gastroesophageal reflux disease. Am J Gastroenterol 95: 2692-2697, 2000.

35. Kaltenbach T, Crockett S, Gerson LB. Are lifestyle measures effective in patients with gastroesophageal reflux disease? An evidence-based approach. Arch Intern Med 166: 965-971, 2006.

36. Moriyama N, Amano Y, Okita K, Mishima Y, Ishihara S, Kinoshita Y. Localization of early-stage dysplastic Barrett's lesions in patients with short-segment Barrett's esophagus. Am J Gastroenterol 101: 2666-2667, 2006.

37. Derakhshan MH, Yazdanbod A, Sadjadi AR, Shokoohi B, McColl KE, Malekzadeh R. High incidence of adenocarcinoma arising from the right side of the gastric cardia in NW Iran. Gut 53: 1262-1266, 2004.

38. Goda K, Kato T, Tajiri H. Endoscopic diagnosis of early Barrett's neoplasia: perspectives for advanced endoscopic technology. Dig Endosc 26: 311-321, 2014.

39. Sharma P, Weston AP, Topalovski M, Cherian R, Bhattacharyya A, Sampliner RE. Magnification chromoendoscopy for the detection of intestinal metaplasia and dysplasia in Barrett's oesophagus. Gut 52: 24-27, 2003.

40. Hamamoto Y, Endo T, Nosho K, Arimura Y, Sato M, Imai K. Usefulness of narrow-band imaging endoscopy for diagnosis of Barrett's esophagus. J Gastroenterol 39: 14-20, 2004.

41. Amano $\mathrm{Y}$, Kushiyama $\mathrm{Y}$, Ishihara $\mathrm{S}$, et al. Crystal violet chromoendoscopy with mucosal pit pattern diagnosis is useful for surveillance of short-segment Barrett's esophagus. Am J Gastroenterol 100: 21-26, 2005.

42. Toyoda H, Rubio C, Befrits R, Hamamoto N, Adachi Y, Jaramillo E. Detection of intestinal metaplasia in distal esophagus and esophagogastric junction by enhanced-magnification endoscopy. Gastrointest Endosc 59: 15-21, 2004.

The Internal Medicine is an Open Access article distributed under the Creative Commons Attribution-NonCommercial-NoDerivatives 4.0 International License. To view the details of this license, please visit (https://creativecommons.org/licenses/ by-nc-nd/4.0/).

(C) 2017 The Japanese Society of Internal Medicine http://www.naika.or.jp/imonline/index.html 